\title{
PENGARUH MEDIA AUDIO VISUALTERHADAP PERKEMBANGAN KOGNITIF ANAK USIA DINI DI TK CENDRAWASIH SAMARINDA
}

\section{THE EFFECT OF AUDIO VISUAL MEDIA ON COGNITIVE DEVELOPMENT}

Muhammad Amir Masruhim, Elin, Evie Palenewen

Universitas Mulawarman

elin92@gmail.com

\begin{abstract}
ABSTRAK
Media audio visual merupakan media yang dapat menstimulus perkembangan kemampuan kognitif anak dengan anak mampu mengenal benda berdasarkan warna dan bentuk, menyebutkan benda berdasarkan warna dan bentuk, dan mengklasifikasikan benda berdasarkan warna dan bentuk. Tujuan dari penelitian ini adalah untuk mengetahui apakah media audio berpengaruh terhadap perkembangan kognitif anak. penelitian ini menggunakan desain pra-eksperimen jenis one group pretest-postest design. Populasi pada penelitian ini adalah 35 anak dengan sampel sebanyak 10 anak. teknik pengumpulan data yang digunakan adalah observasi, wawancara, dan dokumentasi. Teknik analisis data yang digunakan adalah teknik analisis data uji statistik. Berdasarkan hasil perhitungan setelah diberi perlakuan meningkat hingga 45,1\%, pada awal saat pretest perkembangan kognitif anak 40,18\%, kemudian pada saat postest meningkat jadi $85,28 \%$. Dari penjelasan tersebut dapat ditarik kesimpulan bahwa media audio visual memberikan pengaruh terhadap perkembangan kognitif anak kelas B1 usia 5-6 Tahun di TK Cendrawasih Samarinda.
\end{abstract}

\section{Kata Kunci : Media Audio Visual, Perkembangan Kognitif, Anak Usia 5-6 Tahun}

\section{ABSTRACT}

Audio Visual media is a medium that can stimulate the development of cognitive abilities of children with children able to recognize objects based on color and shape, mention objects based on color and shape, and classify objects based on color and shape. The purpose of this research is to find out whether audio media has an effect on children's cognitive development. This study used a pre-eksperimental design type one group pretest-postest design. The population in this studi were 35 children with a sample of 10 children. Data collection techniques used were observation, interviews, and documentation. The data analysis technique used is the statistical test data analysis technique. Based on given treatment increased to $45.1 \%$, at the beginning when the pretest of cognitive development of children was $40.18 \%$, then at posttest it increased to $85.28 \%$. from these results indicate that audio-visual media have an influence on the cognitive development of B1 graders aged 5-6 years in Samarinda Cendrawasih Kindergarten.

Keywords : Audio Visual Media, Cognitive Development, Child Age 5-6 years Old.

\section{PENDAHULUAN}

Salah satu aspek perkembangan yang dikembangkan pada anak usia dini yang telah diatur dalam peraturan menteri pendidikan kebudayaan republik indonesia nomor 137 tahun 2014 tentang standar nasional pendidikan anak usia dini salah satunya adalah perkembangan kognitif.

Pengembangan kemampuan kognitif anak di TK bertujuan untuk mengembangkan kemampuan berpikir anak agar dapat mengolah perolehan belajarnya, dapat menemukan berbagai macam alternatif pemecahan masalah, membantu anak untuk mengembangkan kemampuan logika matematikanya serta 
pengetahuan akan ruang dan waktu, mengembangkan kemampuan memilah-milah dan mengelompokkan, serta mempersiapkan pengembangan kemampuan kognitif anak.

Salah satu media yang dapat mengembangkan kognitif anak adalah media audio visual. Melalui media audio visual dapat merangsang perkembangan kognitif anak dengan menyelesaikan masalah seharihari, mengenal benda-benda disekitarnya, dan menggunakan teknologi sederhana.

Media audio visual yang akan ditampilkan pada anak yaitu cara video tentang mengenal warna video eza dan adi dengan judul belajar mengenl warna merah, kuning, hijau, biru, dan ungu dan video mengenal bentuk dengan judul belajar mengenal bentuk. Tujuan dari video ini ditampikan adalah anak mampu mengenal warna merah, kuning, hijau, biru, ungu , anak mampu mengenal bentuk lingkaran, persegi empat, segi tiga, persegi panjang, anak mampu menyebutkan warna merah, kuning, hijau, biru, ungu, anak mampu menyebutkan bentuk lingkaran, persegi empat, segi tiga, persegi panjang, dan anak mengklasifikasikan warna merah, kuning, hijau, biru, ungu, anak mampu mengklasifikasikan bentuk lingkaran, persegi empat, segi tiga, persegi panjang.

Berdasarkan hasil observasi lapangan peneliti selama melaksanakan Praktik Pengalaman Lapangan (PPL) di TK Cendrawasih Samarinda , secara keseluruhan pembelajaran sudah baik akan tetapi dalam mengembangkan aspek perkembangan kognitif anak masih perlu berbagai variasi dan inovasi kegiatan dalam proses pembelajaran, diketahui media yang digunakan guru kurang optimal sehingga anak menjadi jenuh, cepat bosan. Contohnya pengenalan warna bola lalu menjumlahkan bola yang dipegang guru dan guru juga menggambar dipapan tulis lalu anak maju untuk menjumlahkan yang dilakukan guru untuk mengembangkan kognitif anak kurang menarik bagi anak. sebenarnya di TK banyak media pembelajaran yang dapat digunakan, tetapi guru hanya berfokus kepada satu media saja seperti media berbentuk gambar saja. Berdasarkan hasil penilaian cheklist yang penulis kerjakan setiap harinya juga setelah proses pembelajaran masih banyak anak yang kurang dalam aspek perkembangan kognitifnya.

\section{METODE PENELITIAN}

\section{Jenis Penelitian}

Dalam penelitian ini, penelitian yang digunakan adalah kuantitatif yang dapat diartikan sebagai metode yang berlandaskan pada filsafat positivisme, yang digunakan untuk meneliti pada populasi dan sampel tertentu, teknik pengambilan sampel biasanya dilakukan secara random, pengumpulan data menggunakan instrumen penelitian, analisisdata bersifat kuantitatif/statistic.

\section{Waktu dan Tempat Penelitian}

\section{Tempat Penelitian}

Penelitian ini akan dilaksanakan di bulan Agustus pada semester pertama di Tahun 2018. 
Sungai Kapuas No. 75 Rt. 22 samarinda

2. Waktu

Penelitian ini dilaksanakan di TK Cendrawasih Samarinda Jl.Biola Komplek Prefab Segiri, Kota Samarinda

\section{Target/Subjek Penelitian}

1. Subjek

Subjek penelitian dilaksanakan di kelompok A dan B di TK Cendrawasih Samarinda

2. Objek

Objek Penelitian adalah mengenal warna dan bentuk melalui media audio visiual pada anak didik kelompok B TK Cendrawasih Samarinda

\section{Prosedur}

Penelitian ini menggunakan rublik penilaian, pedoman observasi serta wawancara (tertera di lampiran). Pendekatan Pra Eksperimen menggunakan rancangan One Group Pretest-Poste.

\section{Data, Intrumen, dan Teknik Pengumpulan Data}

Menurut Sugiono, pada prinsipnya meneliti adalah melakukan pengukuran terhadap fenomena sosial maupun alam. Alat ukur dalam penelitian biasanya dinamakan instrumen penelitian. Jadi instrumen penelitian adalah suatu alat yang digunakan mengukur fenomena alam maupun sosial yang diamati. Secara spesifik semua fenomena ini disebut variabel penelitian. Proses pengembangan instrumen dilakukan dengan membuat kisi-kisi instrumen penelitian.

\section{Teknik Pengumpulan Data}

1. Observasi

Bentuk pedoman observasi yang dipakai dalam penelitian ini merupakan pedoman yang berstruktur (memakai kemungkinan jawaban) dan telah ditetapkan indikator-indikator dari setiap jawaban sebagai pegangan pengamat waktu melakukan observasi.

2. Wawancara

Wawancara digunakan sebagai teknik pengumpulan data apabila peneliti ingin melakukan studi pendahuluan untuk menemukan permasalahan yang harus diteliti, dan juga apabila peneliti ingin mengetahui hal-hal dari responden yang lebih mendalam dan jumlah respondennya sedikit/kecil

3. Dokumentasi

Dokumentasi adalah ditunjukkan untuk memperoleh data langsung dari tempat penelitian, meliputi 
buku-buku yang relevan, peraturan-peraturan, laporan kegiatan, foto-foto, filem dokumenter, data yang relevan penelitian.

\section{Teknik Analisis Data}

Teknik analisis data dalam penelitian kuantitatif menggunakan uji statistik dengan menggunakan ttest melalui program SPSS 20.

Teknik analisis data dilakukan dengan memberikan skoring, dta mentah yang dapat diklasifikasikan perkembangan kognitif anak dengan perkembangan skor pada setiap butir amatan, selain itu teknik ini dengan menjumlahkan setiap skor anak, menentukan rata-rata observasi awal dan observasi akhir. Teknik analisis data inferensial pada peneltian ini dilakukan dengan menentukan taraf signifikan, menentukan kriteria penilaian, menentukan uji statistic dan kesimpulan.

Desain Pre-Eksperimental yang digunakan dalam penelitian ini ialah ( One Group Pretset-Posttest Design) dapat dibuat sebagai berikut :

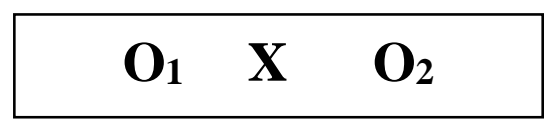

Keterangan :
( Sumber : Sugiono, 2014)

X : Perlakuan

$\mathrm{O}_{1}$ : Nilai Prates (sebelum diberi perlakuan)

$\mathrm{O}_{2}$ : Nilai Postes (setelah diberi perlakuan)

\section{HASIL PENELITIAN DAN PEMBAHASAN}

Berdasarkan hasil pretest pada indikator pertama yaitu mampu mengenal benda dapat diketahui anak yang mendapat skor 1 ada 90\%, anak yang mendapat skor 2 100\%, anak yang mendapat skor 3 0\%, dan anak yang mendapat skor $40 \%$, kemudian berdasarkan hasil pretest pada indikator kedua yaitu menyebutkan benda diketahui bahwa anak mendapat skor 1ada 90\%, anak yang mendapat skor $2100 \%$, anak yang mendapat skor $30 \%$, dan anak yang mendapat skor $40 \%$, kemudian pada hasil pretest indikator ketiga yaitu mengklasifikasikan benda dapat diketahui bahwa anak yang mendapat skor 1 ada $90 \%$, anak yang mendapat skor $2100 \%$, anak yang mendapat skor $30 \%$, dan anak yang mendapat skor 4 $0 \%$.

Berdasarkan hasil postest pada indikator pertama yaitu mengenal benda dapat diketahui bahwa anak yang mendapat skor 1 ada $0 \%$, anak yang mendapat skor $20 \%$, anak yang mendapat skor $390 \%$, dan anak yang mendapt skor $460 \%$, kemudian pada hasil postest indikator kedua yaitu menyebutkan benda dapat diketahui bahwa anak yang mendapat skor 1 ada $0 \%$, anak yang mendapat skor $20 \%$, anak yang 
mendapat skor $390 \%$ dan anak yang mendapat skor 4 60\%, kemudian pada hasil postest indikator kedua yaitu mngklasifikasikan benda dapat diketahui bahwa anak yang mendapat skor $10 \%$, anak yang mendapt skor $20 \%$, anak yang mendapat skor $390 \%$, dan anak yang mendapat skor $460 \%$.

Dengan demikian kegiatan pembelajaran dengan menggunakan audio visual anak sangat antusias, menarik dan aktif untuk mengikuti kegiatan yang berlangsung karena biasanya guru setiap hari menggunakan metode pemberian tugas melalui LKS dan buku.

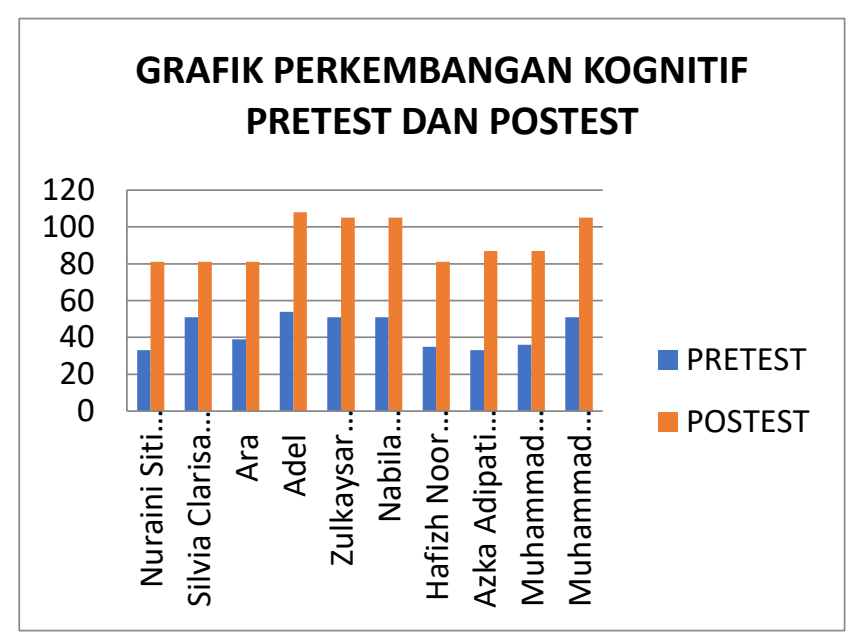

Gambar 1. Hasil Nilai Pretest dan Postest pada Perkembangan Kognitif Anak B1 TK Cendrawasih Samarinda

\section{SIMPULAN DAN SARAN}

\section{Simpulan}

Bedasarkan hasil penelitian, dapat disimpulkan bahwa media audio visual berpengaruh pada kemampuan kognitif anak kelas B1 usia 5-6 Tahun di TK Cendrawasih Samarinda. Hasil perhitungan uji sebelum dan sesudah menggunakan media audio visual menunjukkan bahwa nilai uji sesudah menggunakan media audio visual lebih besar dibandingkan dengan uji sebelum menggunakan media audio visual yaitu meningkat hingga 44,99\%, Pada awal saat pretest perkembangan kognitif anak 40,28\% kemudian pada posttest meningkat hingga $85,27 \%$.

Maka dapat disimpulkan bahwa terdapat pengaruh media audio visual terhadap kognitif anak kelompok B1 di TK Cendrawasih Samarinda tahun 2018.

\section{Saran}

Diharapkan penelitian selanjutnya, hendaknya penelitian ini dapat dikembangkan pula pada aspek perkembangan anak seperti kemampuan berbahasa. 
Yamin, Martinis. Sanana, Jamilah Sabri. 2010. Panduan Pendidikan Anak usia Dini. Jakarta : Gaung Persada (GP).

Sugiono. 2015. Metode Penelitian Pendidikan (Pendekatan Kuantitatif, Pendekatan Kualitatif, dan $R \& D)$. Bandung Alfabeta.

Sugiono, 2014. Metode Penelitian Kuantitatif Kualitatif dan R\&D. Bandung : Alfabeta

Riduwan, 2014. Dasar-dasar Statistika. Bandung : Alfabeta 
